\title{
The Branding of Local Specialty Industry on Keelung Heping Island
}

\author{
Yu-Li Chuang \\ National Taiwan Ocean University, Taiwan \\ Chuang.yuli@gmail.como
}

Publication Information:

Received 31 August 2018, Accepted 29 November 2018, Available online 31 December 2018

doi: 10.21463/jmic.2018.07.2.12

\begin{abstract}
Located to the northeast of Keelung Harbor, Heping Island is one of the earliest places in the development of the history of Northern Taiwan-the first place where the Westerners left their footprints and the Han people began the reclamation of the land. In the early days, the flourishment of the island's fishery industry had attracted immigrants from across the world and eventually turned the island into a unique traditional fishing village. In recent years, fisheries are dwindling and offshore catches have increasingly decreased. With the economic burden and inadequacy of driving forces in local development, the local public is earning less and problems related to employment are on the rise in the fishing village. The severe outflow of population has created a void in inheriting the culture and fishery technology of the fishing villages, leading to the general decline of the development of fishing villages. This research uses Heping Island, Keelung's local branding, as a case study to discover the characteristics of traditional industries by recording, analyzing, and understanding the development of geographical resources, monuments, and lifestyles. At the same time, along with the continuous establishment of the local cultural characteristics, this research transforms the rich and diverse local cultural emotions and memories into indicators of rational analysis, and also into the reference axes of local image design and planning. Through design, with the use of integrated or strategic presentation, the symbolic icons of the local specialty industries are integrated to present the culture, environment, and activities of Heping Island and identify the main image needed for transmission to deliver an overall effective brand planning of the local industries.
\end{abstract}

\section{Keywords}

Branding, Local Specialty Industry, Fishing villages, Heping Island, Keelung 


\section{Research Motivation and Purpose}

The value people attribute to a place of living, through engagement and experience and satisfaction of certain demands, can prompt people to produce symbolic meaning or emotional connection to the area, and thus develop different levels of local identity. The recognition of regional symbols is a kind of attitude, value, thought, belief, meaning, and behavioral intentions of the local people, formed by a sense of belonging to the place of living.

The early development of Heping Island, Keelung, focused more on how to increase the income of the fishermen and less on the overall development of the fishing village and planning strategies. In addition, Heping Island faces the negative factors arising from the downfall of the fishing industry and the changes in economic patterns, leading to the gradual loss of lifestyle, culture, and industrial identity.

Heping Island has had a long history regarding the fishing village lifestyle, along with its specialty industries and humanities style. The transformation and development of traditional industries must be oriented by establishing a new image and creating value, wherein the generation of regional symbols and the value creation of the industries are best suited to the actual situation of the production pattern and industrial transformation of the Heping industries. With the local features of the landscape, humanity, industries, history, and other features related to symbols and images and by presenting Heping Island's resources, cultural contents, and historical significance through the symbolic visual symbols, this research establishes an intuitive visual image and gives a new overall image of the local environment, traditional features, and industrial resources. As such, it helps in developing the positioning and strategy of the management of local industries.

\section{Literature Review}

\subsection{Cultural Landscape and Regional Symbols}

The establishment of symbols is based on human thinking patterns, emotional experiences, and life experiences. Through communicable logical patterns, information is transmitted through meaningful images among people, people and society, and space and time (Yu Chienchang \& Yeh Shuhsien, 1992). The cultural evolution of society and the exchange and application of symbols in information transmission have the function of life experience sharing, information exchange and social interaction (Chang Chengyi, 2012).

Culture is the practice of people throughout daily life and is accumulated in history through the process of practice over a period of time. Cultures accumulated by different people at different times and in different geographic spaces have their own differences and particularities. In other words, it is the behavior of the citizens' daily life practice, the geographical trajectory, and the interaction between behavior and space in a particular time and space.

The cultural landscape contains not only the unique natural ecological community and landscape of a place, but also the story of collective life memory and inheritance of different groups and communities. It also symbolizes the spatial role of 
the industrial structure, political and economic power, power at the grass-roots level, and ideology of a place. The cultural landscape interprets the meaning of the landscape through the physical participation, life practice, or memory of the collection of the emotions of an individual or multiple cultural subjects, and at the same time, shapes the process of identifying the relations between the landscapes. The cultural landscape is also the field of significant competition of the landscapes and the interpretation of the landscapes among different cultural subjects. Whether through discourse or action, the relationship between society and power within the cultural landscape has been constructed. Also, due to the deduction and changes of these relations, the landscape is perpetually in a dynamic process of change.

The establishment of regional cultural symbols is to reconstruct the tangible and intangible regional symbols in the local cultures and become the basic elements and principals of the totem design. Throughout the process of constructing a symbol, exploration for the hidden meaning of local cultural symbols and the representation of in-depth interpretation from multiple perspectives will allow the residents to gain local awareness and perceptual experience, eventually resonating with the significance and perception of the regional symbols (Griswold, 2012). If the image development of local features come with uniqueness, individualization, and local characteristics, combined with specific geographical characteristics, living and cultural connotation, as well as local history, culture, and memory, quenched into a regional cultural symbol, and at the same time, combining relevant industries in the region and turning these into the symbolic image of the region, it will become the core value of the emotional communication of the symbol consciousness in nature and culture (Lin Shuting, 2013; Yang Yufu, 2006).

A local image that is composed of symbolic symbols is the result of a series of physical senses and the context of psychological arousal. It carries a preference for conveying information and generating subjective experience and perception. The construction of a local image will create a circular interaction of attraction, connection, and satisfaction between consumers and products. The regional differences followed by the fusion of the attributes, evaluations, and attitudes of local impression and symbol elements, allow the consumers to gain local awareness and perception experience, and eventually develop the perception and recognition of regional symbols (Kobayashi Satoshi, 1999).

\subsection{Regional Industry}

The development of regional features and regional images is one of the latest economic patterns. Its primary objective is to redesign a new visual imagery and new economic models for the local specialty industries that are dying gradually by utilizing the distinctive image of local cultural conditions or natural resources to develop a symbolic image that carries unique, historical, and cultural characteristics and gains the attention of industrial clusters again (Wada Michio, Kanno Saori, Tokuyama Mitsue, Nagao Masanobu, \& Wakabayashi Hiroba, 2009). Local culture is a kind of content form that is an extension of special topographic features and cultural connotation. It has the characteristics of geographical dependence and is closely connected with the environment, life, and humanistic values. It integrated the history, culture, and emotion of the local people, and formed the industrial pattern based on a rich diversity of local historical culture and collective memory (Akio Tanaka, 2008). Regional settlements comprise people, environment, lifestyle, society, and cultural history. It stands for the accumulation of life experiences in a living environment, and also the recognition of the sense of place that comes with the subjective attachment of emotion and memory to the local space, local environment, living culture, and social structure accumulated over time (Creswell, 2004). The sense of place and the structure of feelings have been accumulated gradually by the local people during their daily lives and the interlacing of the societal system in space and time. In the process, the structure of life and action interacted with each other create a sense of 
place (Li Jinyi, 2006). This value of identity is more than just the experience of living or the relied target for the involvement of regional affection; it also consists of many aspects of knowledge, individual behavior, and social structure, as well as the aspects of memory and identity, and the overall lifestyle.

The formation of a village must possess an area of space and a uniform standard of lifestyle (Chuang Chingta, 1998). Local cultural industries come from the shaping of regional space and environment. They have the characteristics of uniqueness, rarity, and individuality, as well as the strong characteristic of provenance, also known as "Geography Dependency" (Creswell, 2004). Industries derived from its autogenic characteristics come with historical memory and value, and the local features, also known as local uniqueness, is the main factor for the formation of the local cultural system. The coastal area of a fishing village is the place where fishermen live and rest. With strong geographical dependence, there are massive variations in topography, climate, history, culture, and industrial structure. The development of coastal life also gives birth to distinctive local features such as cultural traditions, fishing culture, and marine ecological assets.

The coastal areas of Taiwan are rich in natural resources. The offshore marine living resources are one of the economic dependence of the coastal fishermen, encouraging them to maintain the development of fishery and production of fishery products. The development of the fishing industry in the fishing village economy was once a key development among Taiwan's regional industries, a traditional industry developing from generation to generation; it made significant contributions to the life of the coastal residents at that time (Li Mingyan, 2006). The history of the development of the fishing village, the development and evolution of fishing methods in the fishing village, the derivation of the marine industry, and the diversity of local features are the values of the coastal fishing village community.

In recent years, fisheries are dwindling, and offshore catches have increasingly decreased. With the economic burden and inadequacy of driving forces in local development, people in the region are earning less, and problems related to employment are on the rise in the fishing village. With the severe outflow of population, the cultures and fishery technology of the fishing village are in short of inheritance. The development of fishing villages has generally declined, the traditional industries and culture of the fishing village have not met the needs of today, and the cultural histories and cultural preservation of the fishing village have also not been paid much attention to in the past. Thus, the culture of fishing villages with a low degree of understanding cannot be maintained comprehensively. Fishing villages are facing the crisis of hollowing out under the vicious cycle (Chuang Chingta, Ho Lite, \& Liao Chunpei, 2015). The value preservation and continuation of the transformation of the fishing culture should be integrated into the life of the residents. With the geographical dependence characteristic of the fishing village, the content industries emerging out of the cultural connotation of fisheries, which are rare and unique, and the mutual development of the establishment of cultural totems and the regeneration of industry can represent the natural or cultural environment of the fishing village. At the same time, it creates vibrant and high-quality living conditions and the environment in fishing villages. This will revive the culture and industry of the fishing village, as well as drive the region into achieving self-sufficient economic revitalization and sustainable development (Lin Shuting, 2013).

\subsection{Heping Island}

Heping Island, Keelung, is one of the earliest places in the development of Northern Taiwan. Heping Island, formerly known as "Sheliao Island," is an island separated from the mainland by a trench. Heping Island is located at the doorway to the Keelung Harbor, a must-stop for sea routes, which controls the entry and exit of ships (Figure 1). Ever since the 
East Asian trade era began in the 16th century, it has been the place where military powers compete. It was the first place in Taiwan where Westerners resided, and one of the first places in Keelung where the Han people cultivated. The convergence of currents in the adjacent sea areas of Heping Island creates an excellent fishing ground, and the long and tortuous coasts provide a suitable living environment for fishing villages, which has eventually turned into a unique traditional fishing village settlement. The island is subjected to year-round northeast monsoon winds, and the erosion of the waves has caused Heping Island to have a unique rock landscape. On the other hand, there is also an abundance of rare flora and fauna on the coast. The island is often the focus of attention due to its hundreds of years of history. The changes in lifestyle, ethnic culture, and industry show the development and diversity of the place.

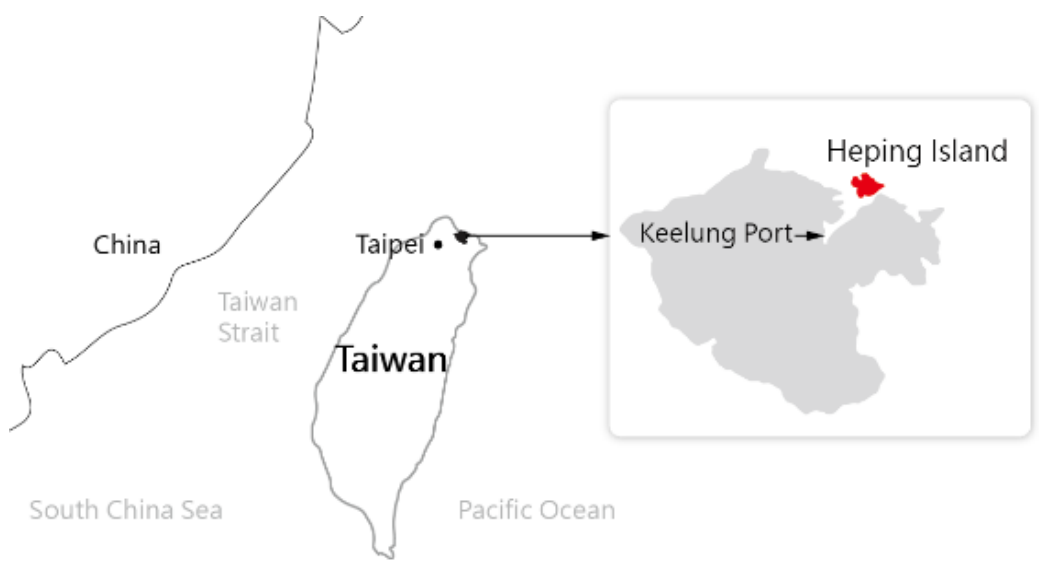

Fig 1. Heping Island's Geographical Location

\subsection{History and Humanistic Values}

The evolution of the history of Heping Island can be divided into the Ketangalan's Great Kelang (literally "Great Hencoop") Era, the East Asian Trading Era (Spanish and Dutch occupation period), which started at the beginning of the 16th century, the Han Ruling Era (period of Ming and Qing Dynasty), the short period of French occupation, the Japanese Government Era, and the Post-liberation development. (Tu Chenyuan, 2012). In the early days, a settlement of the Ketangalan Tribe resided in Heping Island. Due to the geographical location, it is a must-stop for sea routes. The importance of its port location and the mineral resources in its vicinity has led to its constantly changing occupation by powerful forces. In the 16th century, Western powers started the "East Asian Maritime Era," and it became a battleground between the Spanish and the Dutch. The Spanish actively built up fortresses, including Fort San Salvador, which was built on Heping Island. They constructed a fortification to defend the port and the river, and it became the earliest military garrison in Northern Taiwan. Other than that, it also became the vital base for the development of overseas trade (Figure 2).

During the Qing Dynasty's occupation of Taiwan in 1863, Chinese immigrants from Fujian and Guangdong started migrating to Heping Island. During the Japanese ruling period, large numbers of Japanese, Ryukyuan, and Koreans moved to the island bringing along their fishery culture. They also had the fisherman's quarters planned, and the golden 
period of the fishery industry began. During the post-liberation period, the popularity of the fishery industry sustained from the Japanese ruling period. The fishery and shipbuilding industry of Heping Island is based on the existing foundation established by the Japanese. Business was still booming along the inner side of the port, and it has transformed Heping Island from a small and isolated fishing village to a modern industrial fishing village.

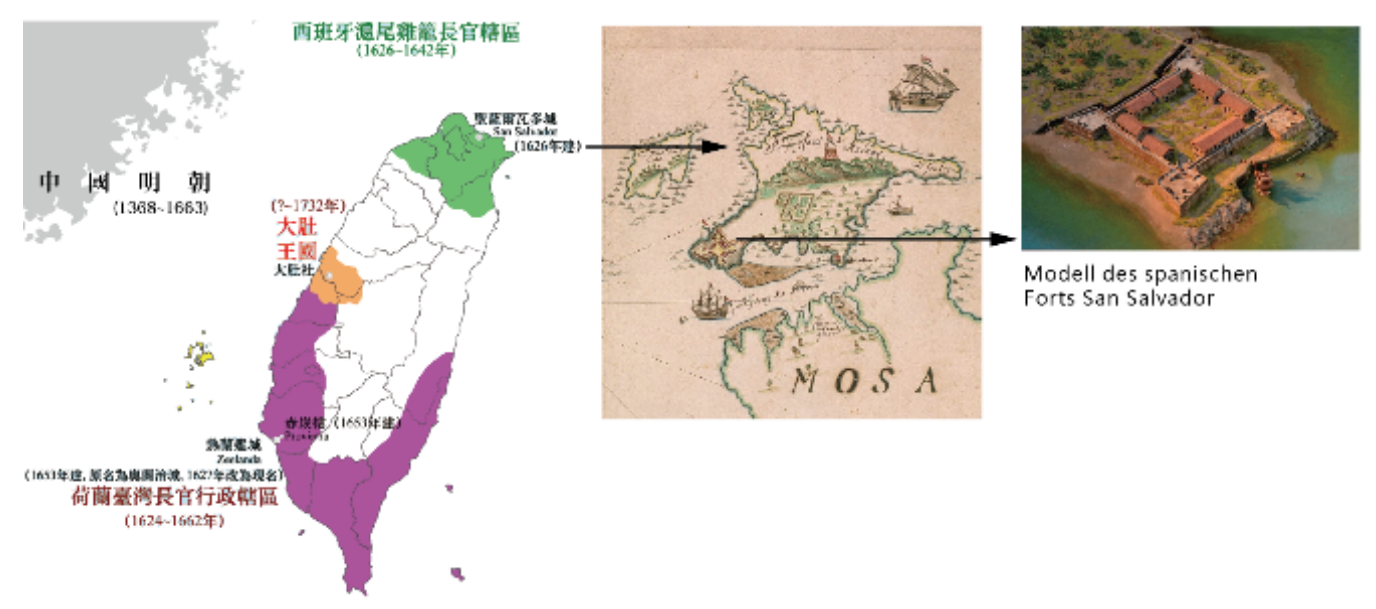

Fig 2. Spanish Formosa \& Modell des Spanischen Forts San Salvador (https://en.wikipedia.org/wiki/Spanish_Formosa)

\subsection{Natural Terrain}

Heping Island is surrounded at a radius of about four kilometers by the "Talio Formation" subsidence coast. The abrasion platform is quite developed and eased out outward along slopes, and the stratum inclines to the coastline, forming the topographic features of a high-north and low-south and mountainous straight coast. Due to the different corrosion resistance ability of the Talio formation, the sea erosion caused by strong winds and abundant rains throughout the year, and also the long-term exposure of the coastline to the northeast coast strong current effect, the sea erosion topography is especially developed. Coupled with the long-term impact of seawater and potent effects of sea erosion, the sea erosion topography is developed abnormally and has caused indentations on the rock or erosions along the hardness difference of the rocks, resulting in precious and unique geological landscapes such as capes, trenches, sea cliffs, sea erosion platforms, monomorphic rocks, and tofu rocks (Figure 3). The diversity of the sea erosion topography has created connections between the activities, landscapes, and cultures of the island, as well as the phenomena and functions of various topographic environments, which created a distinctive landscape and became the foundation of the development of the unique local landscape. 


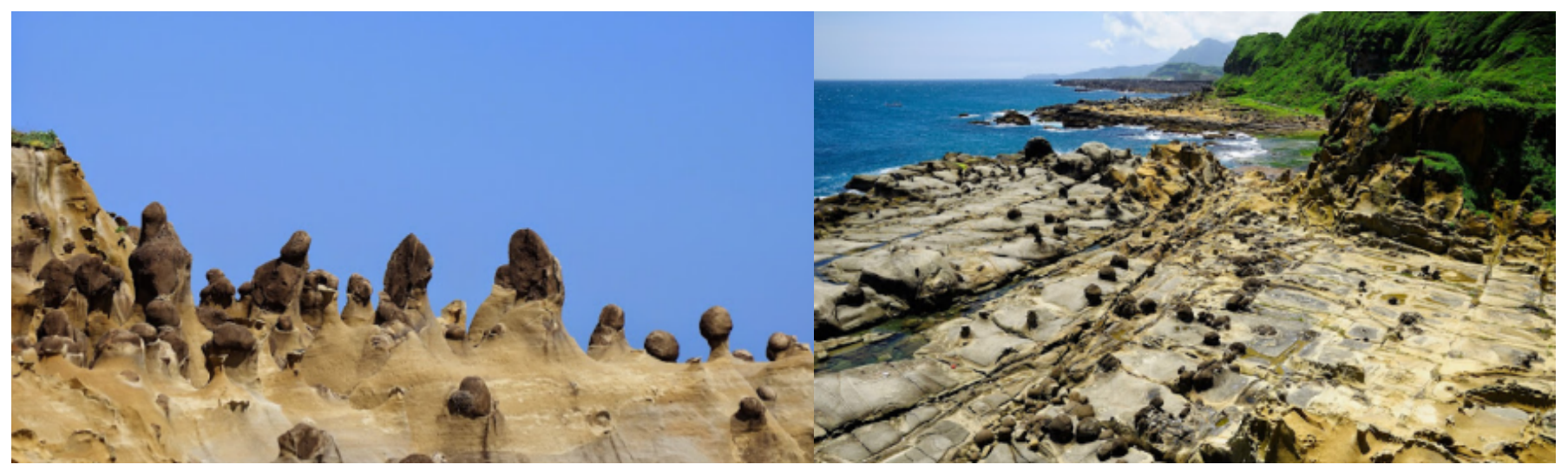

Fig 3. Sea Erosion Topology of Heping Island (http://ipolita.blogspot.tw)

\subsection{Local Industry}

The natural harbor of the Heping Island along with its long and winding coastline with warm currents has provided a suitable living environment for fishing villages. With the confluence of black tides, the open sea forms an excellent fishing ground. The people of Heping Island live on the sea; the industries have been mostly related to the sea since ancient times. The early development of fisheries on Heping Island has attracted immigrants from all over the world, and gradually, it has grown into a typical traditional fishing village that relies on fisheries. During the Japanese ruling era, the excellent fishing grounds and abundant species of fish attracted a large number of Japanese, Ryukyu, and Koreans to Heping Island. They built a modern fishing port and brought in new fishing technologies. Some public facilities in the fishing ports such as gas stations, frozen ice factories, fish processing factories, shipyards, fish markets, fishery radio stations, and other peripheral industries have also been set up successively.

Different fishing operations have been developed with the emergence of fish stocks and the change of seasons, creating a large number of employment opportunities and attracting foreign population from all over the world, including the Ryukyuan people who did dive fishing, Japanese fishermen who engaged in aquaculture, and Hokkien people who migrated to settle in Taiwan. The integration of diverse ethnic groups transformed the tranquil and simple fishing village into a modern industrial fishing port.

The Heping Island coast abounded with red agar. The harvest period of agar lasted from May to August. Many fishermen would come during this period to collect the agar, their primary source of income. The huge platform formed at the intertidal zone when the coast recedes is rich in biological resources. Among them, algal plants are the most widely distributed, such as red algae in summer and green algae in winter and spring. The locals would come to gather agar, black moss, and many kinds of seaweeds during different seasons and create healthy food or add the algae ingredients into food. It is the staple crop for Heping Island's economic development (Figure 4).

However, during the 1970s, the fishing grounds of Heping Island had started to gradually dry up, and the catches began reducing substantially. Besides, the changes in societal patterns also discouraged the younger generations from engaging in hard work such as fisheries. The downturn in the fishing industry impacted the surrounding related industries, causing the outflow of the younger generation. Previously, Heping Island had attracted many immigrants from 
other places due to various factors such as the industry and war. However, due to the decline in the industries, the population began dwindling. At this time, there were incessant calls to bring about the development of Heping Island through the use of the tourism industry. However, the shrinking resources in offshore fisheries faced a shift in economic patterns. To smoothly promote the image regeneration of Heping Island and create a new page for development, a SWOT analysis is carried out on the status of the resources and industries of Heping Island as shown in Table 1:

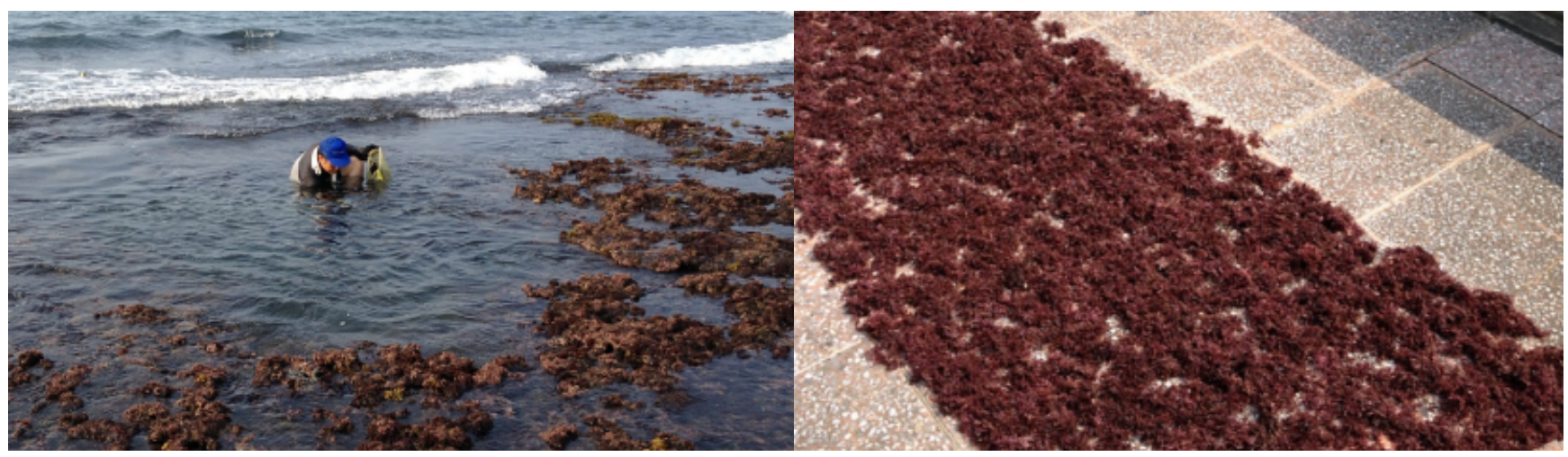

Fig 4. Heping Island Agar Collection Process (http://blog.xuite.net/joey_yeh/blog/213741808)

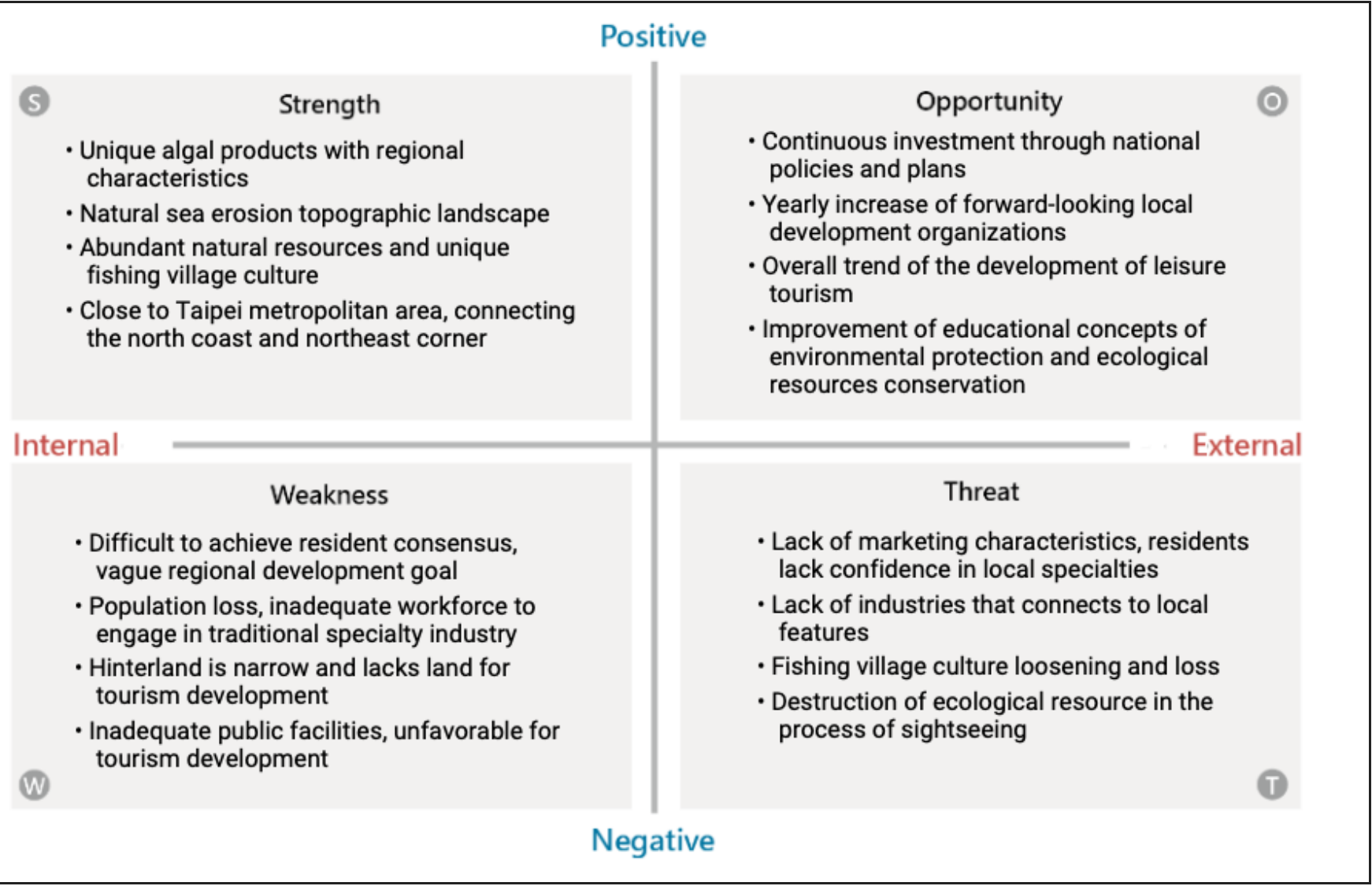


According to the SWOT analysis in the branding proposal of Heping Island's fishing village specialty industries, it can be seen that there are many advantages and opportunities for development. The local features and abundant natural resources of Heping Island can be developed into a diversity of economic themes. The only thing is lacking is the planning and marketing of the recognition of the local culture and the overall image of the region. If established, it can improve the overall development of the regional economy of the fishing villages.

\section{Design and Production of Heping Island's Local Specialty Industry Brands}

The place possesses the features of history, culture, and daily life, and thus has certain brand benefits such as identity and uniqueness. Local brands can offer an identity to the people, events, and things of the particular region, and also the function of extended association; hence, the association strength of consumers on the provenance is often better than other associations. As seen, the place's image is, in fact, the core strategy of local brands. A place's image with market attractiveness not only increases the reputation of the place itself, but it also offers a brand extension and is able to ensure the brand equity of its products.

This research divides the complete design process into two stages, the exploration of the cultural landscape and expression of local icons (Table 2).

Table 2. Design Process of Heping Island's Local Specialty Brands

\begin{tabular}{|l|l|l|}
\hline \multirow{2}{*}{ Exploration of the Cultural Landscape } & On-site Observation & Experience and Understanding \\
\cline { 2 - 2 } & Information Gathering & \\
\cline { 2 - 2 } & Sorting and Analysis & \\
\hline \multirow{2}{*}{ Expression of Local Icons } & Image production & \multirow{2}{*}{ Understanding and Expression } \\
\cline { 2 - 2 } & Expression of Icon Design & \\
\hline
\end{tabular}

\subsection{Exploration of the Cultural Landscape}

The first stage is to chiefly understand the various sides of the cultural landscape of Heping Island and to acknowledge the associated cultural landscape dimensions of the specialty industry with respect to the natural environment, history, and humanistic values of Heping Island through the study, analysis, and actual survey experience of the landscape (Figure 5, Figure 6). 


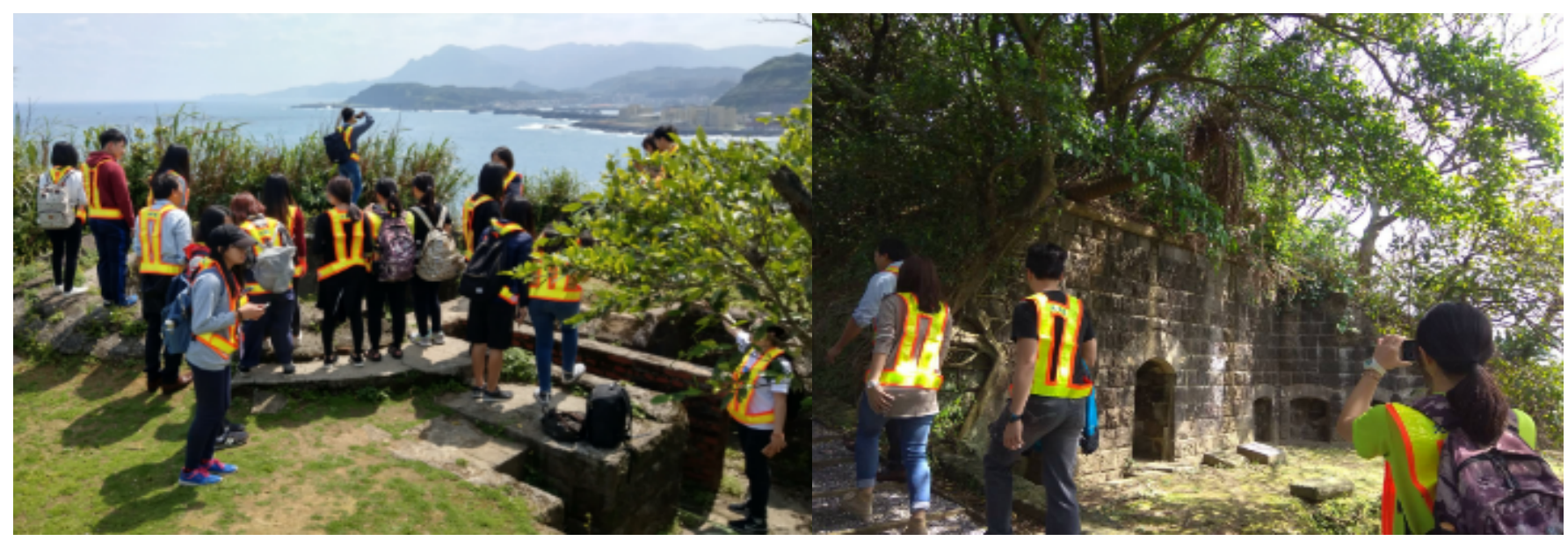

Fig 5. Field Research of Heping Island

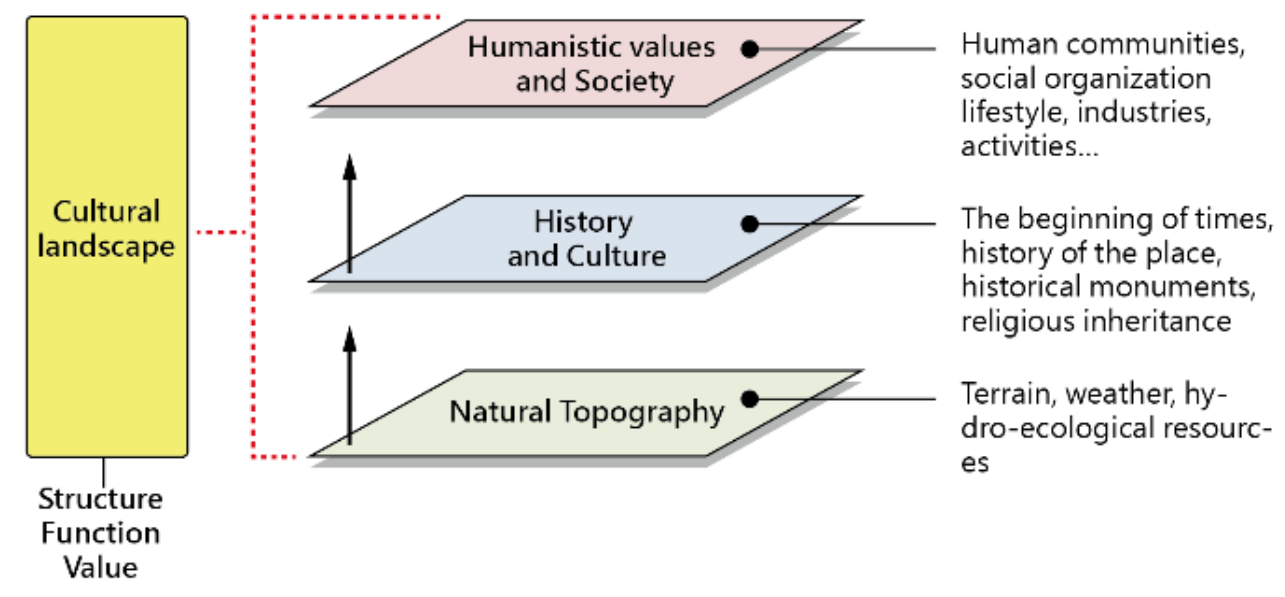

Fig 6. Heping Island's Cultural Landscape Dimensions

Also, this stage aims to collate and gather image elements of Heping Island through the gathering and analysis of relevant literature. Hence, concluding the various aspects such as natural cognitive image, abstract emotional image, and overall image, all belonging to Heping Island, to explore the transfer of images and design issues (Figure 7). 


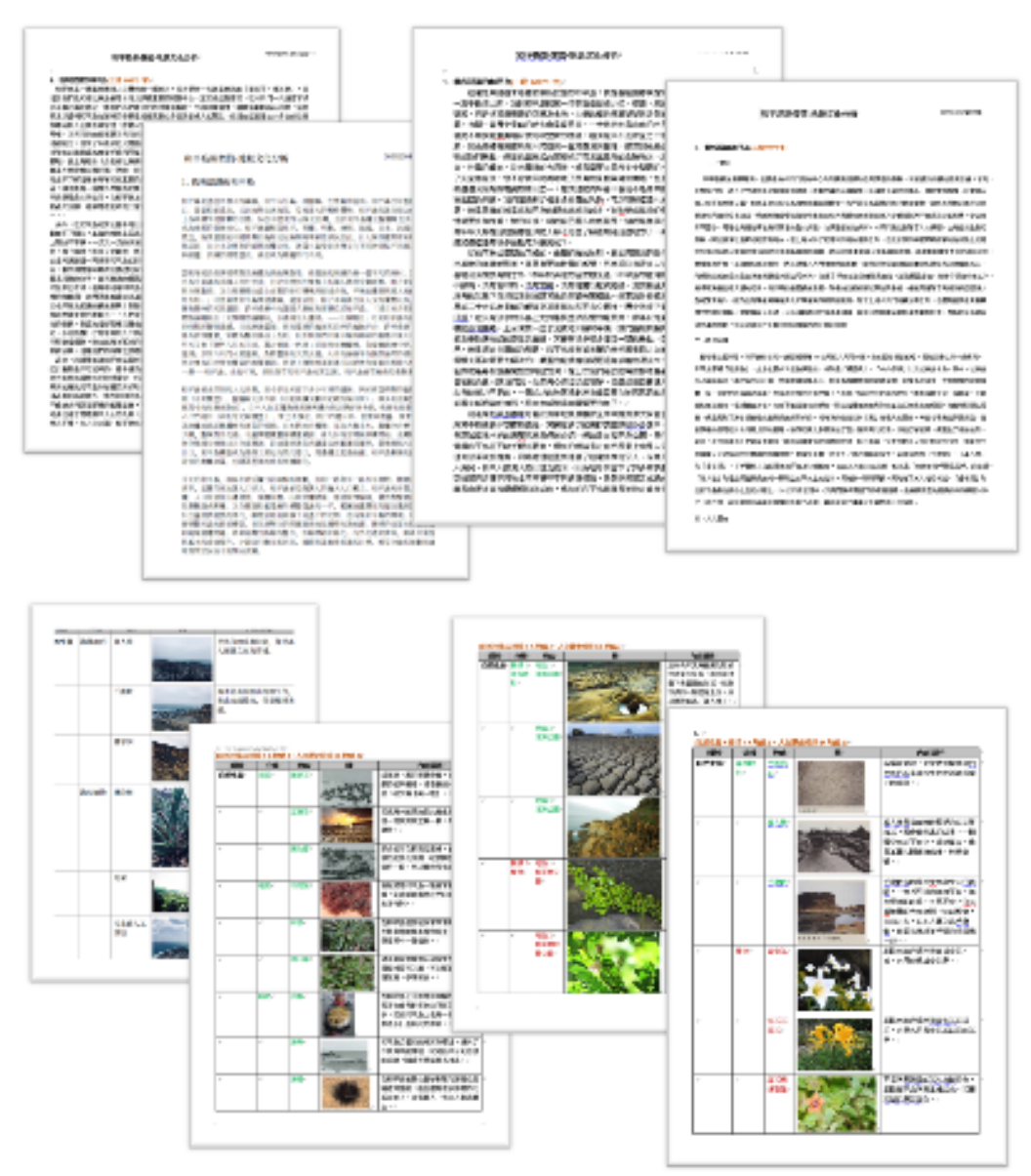

Fig 7. The Collation and Analysis of Literature of the Cultural Landscape of Heping Island

\subsection{Expression of Local Icons}

In the second stage, the primary development is the reproduction of local symbols. The design and development of symbols must be in accordance with their metaphorical properties to make it possible for them to be schematized and disseminated. This research constructs symbolic icons conversion through the use of various natural environments, historical, and cultural activities with past memories of Heping Island (Table 3). 
Table 3. Reproduction of Local Symbols

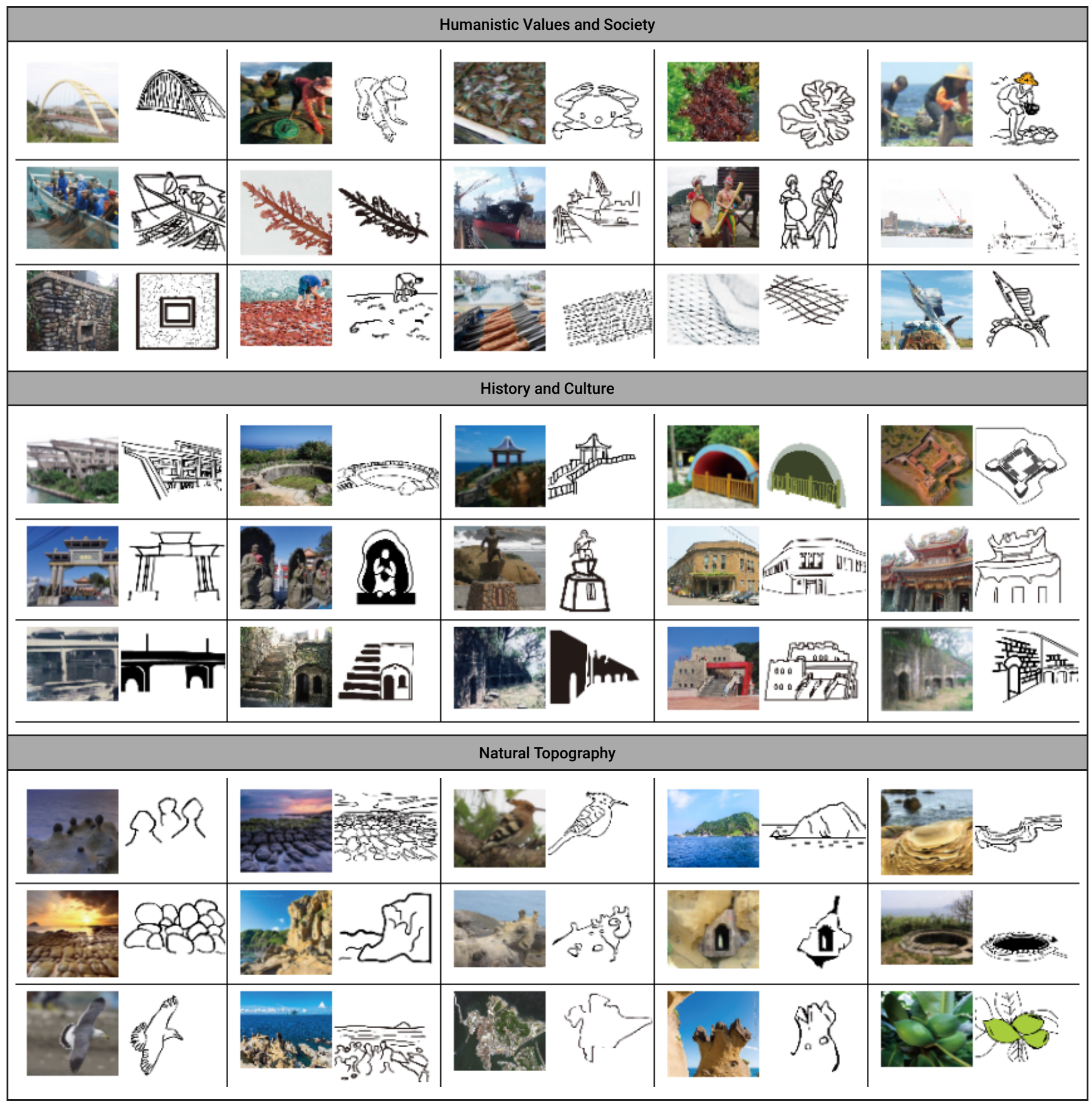

At the same time, this stage reintegrates the existing island symbols imagery from three perspectives and levels-the characteristics of Heping Island's marine environment, the characters of its name, and the island's image-to show and explain the visual form, content, and meaning of Heping Island. This provides a referable symbol for identity development, allowing the primary symbol image to invoke the collective memories of emotions of the region and the economic value application of more diverse and profound symbols (Figure 8). 

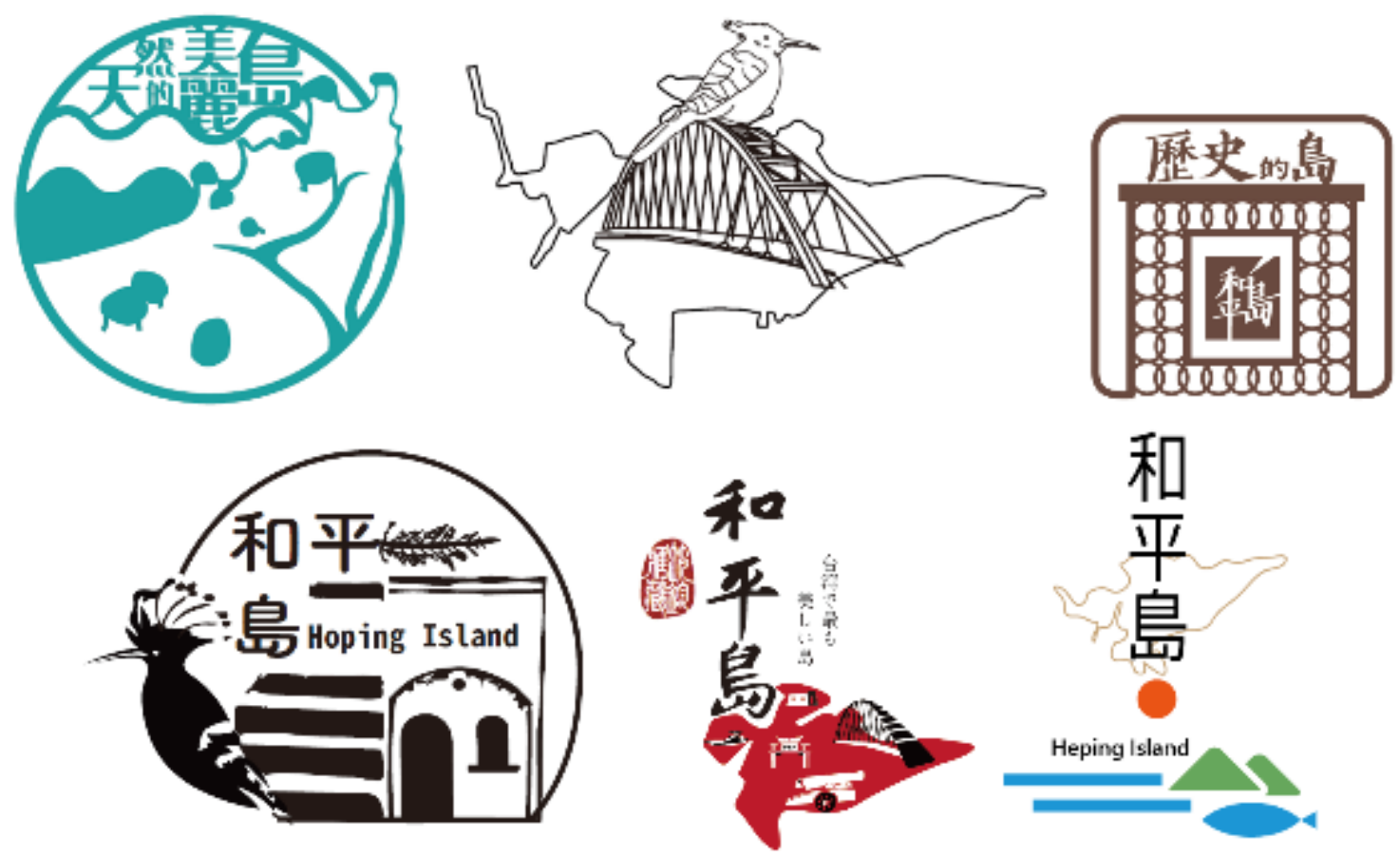

Fig 8. Combination of Images

The chosen images are those that use the natural environment, industrial pattern, and topology characteristics of Heping Island as the primary form of image expression, with the use of smooth lines and simple blocks to give rise to a new form of symbols that represent Heping Island (Figure 9). At the same time, the application of low brightness of the four colors-brown, orange, green, and blue-provides an association to the local atmosphere of Heping Island, establishing an intimate connection and using the perception of color to delve into the more in-depth cultural metaphor and imagery (Table 4).

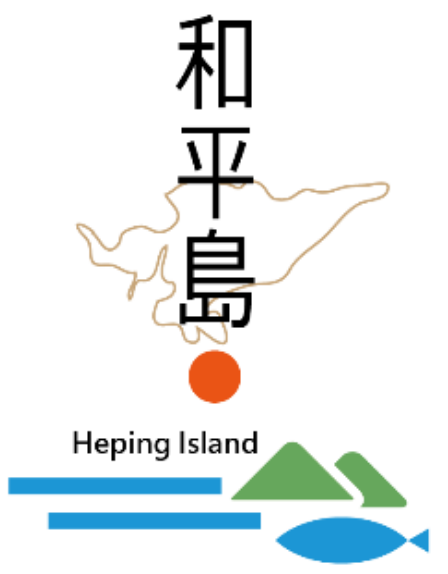

Fig 9. Heping Island's Local Specialty Industry Brand 
Table 4. Explanation of the Imagery of the Icon's Colors

\begin{tabular}{|l|l|l|}
\hline Icon & Color & \\
\hline & Brown & Filled with the primitive nature feature, this color presents a nostalgic and simple sense of inclusiveness \\
\hline & Orange & Symbol of strength and happiness, this color expresses the new worth of Heping \\
\hline & Green & Expresses a sense of vital energy \\
\hline & Blue & Expresses the concept of liveliness, extensiveness, and vastness \\
\hline
\end{tabular}

Building a brand image is not only an expression of design, but it is also the realization of the life situation and cultural value. The brand image of a local specialty industry brand formed through the various implicit and explicit constituting elements of local culture not only showcases the characteristic form of the terrestrial environment but also expresses the cultural implication and different aesthetic styles behind it. At the same time, appropriate applications such as product packaging and expression of visual imagery can further establish and integrate the place's characteristics and spending activities (Figure 10).
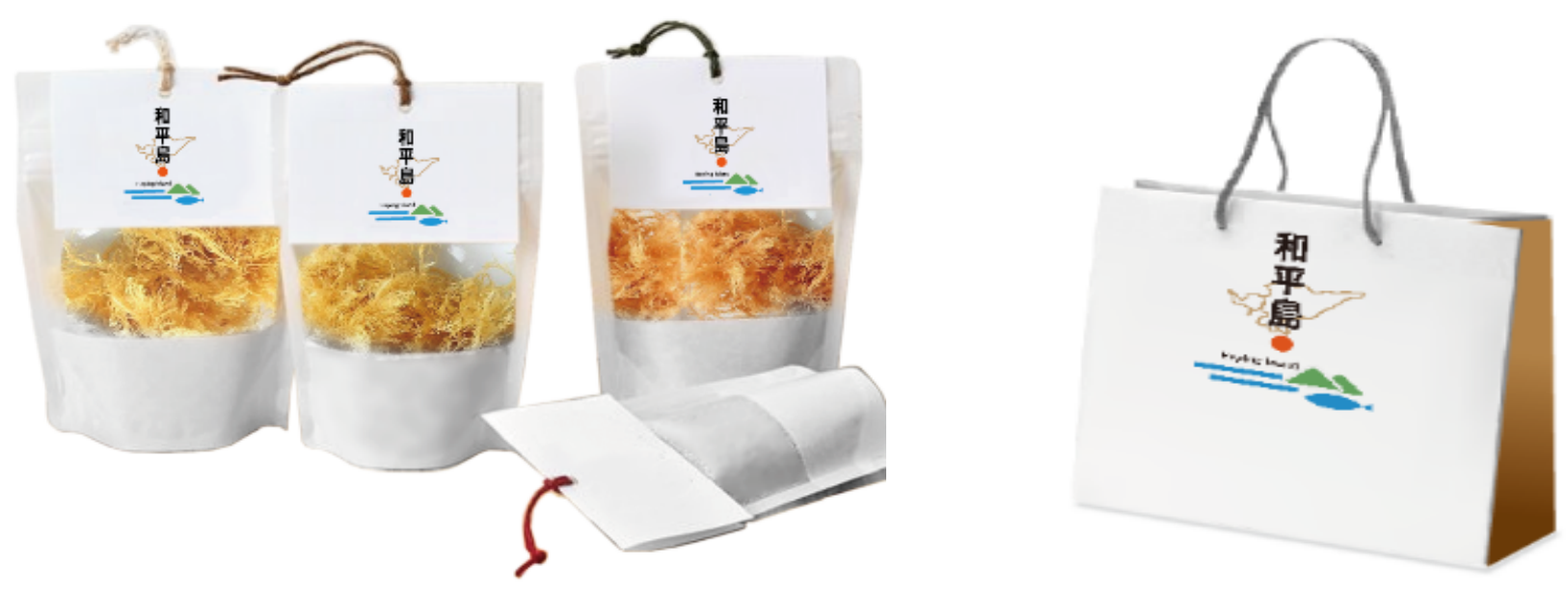

Fig 10. Creative Design and Packaging Application of Heping's Visual Imagery 


\section{Research Conclusion and Suggestions}

\subsection{Research Conclusion and Discussion}

Taiwan is surrounded by the sea; the culture stemming from the sea is among the features of regional development. This culture is a marine culture with different features, which is developed by integrating the environmental characteristics and marine lifestyles of various regions. Heping Island is a traditional fishing village of a coastal living settlement, which showcases the multiple faces of the marine culture. In recent years, the advanced technology in fishing equipment has caused a blow to the old economic industry of the small fishing village. Lifestyle transformation has become the existing general issue of coastal fishing villages. In the revitalization of the regional industrial development, the experience in fishery development and the historical and cultural characteristics of fishing villages are the essential cornerstones in the conversion of marine culture symbols. Through the conversion and design of symbols with local characteristics, the image and meaning of the fishing village culture and cultural icons of specialty products can be newly defined and shaped. Transforming the value and availability of cultural resources in fishing villages can break through the weak economic restraints of the industry and strengthen the relationship between local culture and value creation; this should be one of the essential directions in which the future developments of the local industry should head. This research attempts to transform Heping Island's symbols with regional characteristics and design them into new totems. It also extends to the visual application on related products, in hope of enhancing the cultural significance and symbolic implication of the product, and creating new thinking for the improvement of the value of fishing villages' lifestyle products.

\subsection{Suggestions for Follow-up Research}

This research only utilizes a single case study to explore the correlation of resources, design expression, and value creation of local cultural features in the design and application process. In the future, it is suggested to not only transform cultural assets into new totems in research concerning fishing village culture and related topics, but also, after the emergence of the new totems, see the multi-aspect presentation of all solid carriers and the representation of cultural characteristics through the use of the electron carriers with a remote transmission. At the same time, a more indepth investigation can be done on these different levels of conversion benefits.

\section{References}

Chang Chengyi, 2012. The Translation of Culture Symbol: An Example of Bamboo Appliances Design. (Master), National Taiwan Normal University, Taipei.

Chuang Chingta, Ho Lite, Liao Chunpei, 2015. Vision to Practice of Fishing Community Regeneration - Experience of BaDouZi Community. Fisheries Extension Report, 44, 57-84. 
Chuang Chingta, 1998. A Research on Key Success Factor in Reconstruction and Development of Fishing Village in Taiwan Area National Science Council (NSC) Research Grant Final Report.

Creswell, T, 2004. Place: A Short Introduction Jun. Chichester: Wiley-Blackwell.

Griswold, W, 2012. Sociology for a New Century Series (4th ed.). New York: SAGE.

Kobayashi, S, 1999. Brand. Best. Marketing. Management Research, 49(4), 125.

Li Jinyi, 2006. "Sense of Place" and It's Many Manifestations on the Interior and Exterior of Local Museum-Case Study of Nan-Fang-Ao Fishing Village. (Master), National Chiao Tung University, Hsinchu.

Li Mingyan, 2006. Study on the Regenerational Strategy of A Fishing Village: Cheting Township of Kaohsiung County in Taiwan as the Case. (Master), National Sun Yat-sen University, Kaohsiung.

Lin Shuting, 2013. Researching and Creating the Visual Packaging Design for Local Culture Agricultural Products: A case Study of Chianan area Agricultural Products Packaging Creation. (Master), National Taiwan Normal University, Taipei.

Tanaka, A 2008. Build a Regional Brand. Tokyo: Kobunsha.

Tu Chenyuan, 2012. Rethinking and Reconstructing local narratives of Keelung's Hoping Island - A critical study via Cartographic Analysis and remapping. (Master), National Taiwan University, Taipei.

Wada, M, Kanno, S, Tokuyama, M, Nagao, M, \& Wakabayashi, H, 2009. Local Brand: Management. Tokyo: Yuwakaku.

Yang, Yufu, 2006. Design and Culture : design, sign, communication. Taipei: Asia Book.

Yu Chienchang, Yeh Shuhsien, 1992. Semiolieo:Language \& Art. Taipei: JIOUDA. 